\title{
Optimization of hyperthermia and dendritic cell immunotherapy for squamous cell carcinoma
}

\author{
KOUSHI MATSUMOTO ${ }^{1}$, NORIYUKI YAMAMOTO ${ }^{1}$, SUMITAKA HAGIWARA $^{1}$, MASAKI SAITO $^{1}$, \\ HIROKI FURUE ${ }^{1}$, TOSHIO SHIGETOMI ${ }^{2}$, YUJI NARITA ${ }^{3}$, KENJI MITSUDO ${ }^{4}$, \\ IWAI TOHNAI ${ }^{4}$, TAKESHI KOBAYASHI ${ }^{5}$ and MINORU UEDA ${ }^{1}$
}

\begin{abstract}
${ }^{1}$ Department of Oral and Maxillofacial Surgery, Nagoya University Graduate School of Medicine; ${ }^{2}$ Department of Oral and Maxillofacial Surgery, Nagoya City University Graduate School of Medical Sciences; ${ }^{3}$ Department of Cardiac Surgery, Nagoya University Graduate School of Medicine, Nagoya; ${ }^{4}$ Department of Oral and Maxillofacial Surgery, Yokohama City University Graduate School of Medicine, Yokohama; ${ }^{5}$ College of Bioscience and Biotechnology, Chubu University, Kasugai, Japan
\end{abstract}

Received November 17, 2010; Accepted December 30, 2010

DOI: 10.3892/or.2011.1232

\begin{abstract}
The aims of this study were to explore the feasibility of a novel combination therapy comprising hyperthermia (HT) and dendritic cell (DC) application for squamous cell carcinoma (SCC), and to optimize the conditions of this therapy. In vitro, the correlation between maturation of DCs by co-culture with SCCVII cells and HT was investigated. DCs did not mature in simple $\mathrm{HT}\left(43^{\circ} \mathrm{C}\right.$ for $\left.30 \mathrm{~min}\right)$ with SCCVII cells. On the other hand, DC maturation occurred in additional mild HT (mHT: $41^{\circ} \mathrm{C}$ for $30 \mathrm{~min}$ ) with simple HT. To assess whether additional mHT was effective, in vivo combined treatment was performed using tumor-bearing $\mathrm{C} 3 \mathrm{H} / \mathrm{HeJ}$ mice. A more suppressive effect of tumor growth was observed, and cytotoxic $\mathrm{T}$ cell infiltration was significantly increased by adding mHT compared to conventional only simple HT with DCs. These phenomena also occurred in non-treated contralateral tumors as well as treated ones. Our data suggest that the combination of $43^{\circ} \mathrm{C}$ preheated simple HT SCCVII tumors and additional $41^{\circ} \mathrm{C}$ heat mHT promotes DC maturation, resulting in suppression of tumor growth systemically and lifetime prolongation in mice. A three-step process of additional mHT after local HT and intratumoral immature DC (iDC) injection could be a more effective and novel method for the treatment of SCC.
\end{abstract}

\section{Introduction}

Recently, the local control rate of head and neck cancer, the majority of which are squamous cell carcinoma (SCC), has

Correspondence to: Dr Noriyuki Yamamoto, Department of Oral and Maxillofacial Surgery, Nagoya University Graduate School of Medicine, 65 Tsurumaicho, Showaku, Nagoya 466-8550, Japan

E-mail: noriyuki@med.nagoya-u.ac.jp

Key words: hyperthermia, dendritic cell, squamous cell carcinoma, immunotherapy, magnetite cationic liposome improved. However, these advanced cancers, especially in the case of recurrence and metastasis, become refractory to conventional therapies, and the adverse side-effects of these therapies become even more frequent and severe. Even as a palliative therapy, another modality to trigger other anti-cancer mechanisms is desired to treat SCC. Recently, it appears that hyperthermia (HT) activates anti-cancer immunity through the expression of heat shock proteins (HSPs) from heated cancer cells $(1,2)$. HSP-tumor peptide complex is actively endocytosed by antigen presenting cells (APCs) via several HSP receptors (3-5). The use of HT and dendritic cells (DCs) may be a possible approach to immuno-induction because DCs are the most potent APCs. Our previous study actually revealed that combination therapy with immature DC (iDC) injection directly into tumors after local $\mathrm{HT}$ at $43^{\circ} \mathrm{C}$ using magnetite cationic liposomes (MCLs) is a possible approach to immune induction in melanoma and T-lymphoma $(6,7)$. We hypothesized that therapy combining HT with DC may also be effective for SCC. In this study, effects of HT with DC were examined. Recent studies reveal that the timing, temperature and duration of heating are important to activate anti-cancer immunity effectively (8). Thus, optimization of the combination therapy to yield a marked effect on SCC was also investigated.

\section{Materials and methods}

Cell lines. SCCVII cells formed the spontaneously arising squamous cell carcinoma of $\mathrm{C} 3 \mathrm{H}$ mice. SCCVII cells were cultured in DMEM (Gibco BRL, Gaithersburg, MD), supplemented with $10 \%$ FBS (PAA Laboratories, Austria).

Animal models. Seven-week-old female $\mathrm{C} 3 \mathrm{H} / \mathrm{HeJ}$ mice were purchased from Chubu Kagaku Shizai (Nagoya, Japan) and maintained in our animal facility. The experimental protocol in the present study was approved by the Animal Care Committee of Nagoya University School of Medicine. Animal experiments were performed according to the principles laid down in the Guide for the care and use of laboratory animals 


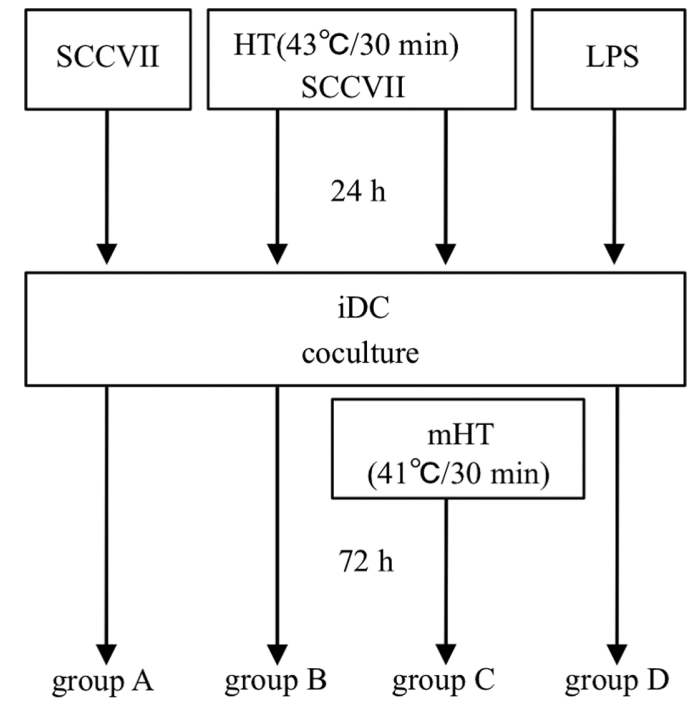

Figure 1. The protocol of DC maturation assay in vitro. iDCs cocultured with non-heated SCCVII cells were designated as group A, and those with $43^{\circ} \mathrm{C}$-heated SCCVII were group B. Just after DCs were cocultured with heated SCCVII cells, $41^{\circ} \mathrm{C}$ mild HT (mHT) was performed under the coculture (group C). For positive control, iDCs were stimulated with lipopolysaccharide (LPS) (group D).

prepared under the direction of the Office of the Prime Minister of Japan.

Hyperthermia treatment in vitro. Dishes (10-cm) containing $80 \%$ confluent SCCVII cells $\left(\sim 1 \times 10^{7}\right)$ were immersed in a temperature-controlled water bath maintained at 41, 43 and $4^{\circ} \mathrm{C}$ for $30 \mathrm{~min}$.

Western blot analysis. Expression of HSP70 by heated SCCVII cells was evaluated by Western blotting, according to a previous study (9). Mouse anti-Hsp70 antibody (clone, C92F3A-5; StressGen Biotechnologies, BC, Canada; 1:1000) was used as a primary antibody. HSP70 is a major HSP finding increasing use in tumor immunotherapy (10).

Dendritic cell preparation. Bone marrow cells were harvested from the tibia and femur of $\mathrm{C} 3 \mathrm{H} / \mathrm{HeJ}$ mice, following an established protocol (11), and the cells were plated as $1 \times 10^{6} / \mathrm{ml}$ of culture medium consisting of RPMI-1640 supplemented with $10 \% \mathrm{FBS}$ and $10 \mathrm{ng} / \mathrm{ml}$ recombinant murine GM-CSF (PEPROTECH, Rocky Hill, NJ). After 8 days culture with cytokine supplementation on alternate days, the cultured cells could express CD11c which was confirmed by flow cytometry. These prepared cells were iDCs because they expressed a small quantity of CD80 and MHC class II.

Dendritic cell maturation assay. Twenty-four hours after in vitro $\mathrm{HT}$ at $43^{\circ} \mathrm{C}, 5 \times 10^{6}$ non-heated or heated SCCVII cells were added to the iDC-cultured dishes. iDCs cocultured with non-heated SCCVII cells were designated as group A, and those with heated SCCVII were group B. Just after DCs were cocultured with heated SCCVII cells, $41^{\circ} \mathrm{C}$ mild HT (mHT) was performed under the coculture (group $\mathrm{C}$ ). For positive control, iDCs were stimulated with lipopolysaccharide (LPS) (group D). The protocol is shown in Fig. 1. After 72-h cocul- ture, DCs were assessed by flow cytometry in every group. Cocultured DCs were collected and washed with cold PBS and were then incubated at $4^{\circ} \mathrm{C}$ for $45 \mathrm{~min}$ with the fluorescein isothiocyanate (FITC)-conjugated monoclonal antibodies (eBioscience, San Diego, CA) against murine cell-surface molecules MHC class II, CD80 and the PE-conjugated monoclonal antibody against CD11c (eBioscience). Stained cells were analyzed by flow cytometry. The cells used in this experiment were gated by a CD11c-positive region to detect only DCs. Flow cytometry was performed on a FACSCalibur $^{\mathrm{TM}}$ Flow Cytometry System (BD Bioscience).

Preparation of magnetite cationic liposome. To perform efficient HT in vivo, MCLs were used in this study. They were fabricated from a colloidal magnetite and lipid mixture consisting of N-(a-trimethylammonioacetyl)-didodecyl-Dglutamate chloride (Sogo Pharmaceutical, Tokyo, Japan), dilauroylphosphatidylcholine and dioleoylphosphatidylethanolamine (Sigma Chemical, St. Louis, MO) in a 1:2:2 molar ratio, as described previously (12).

Animal models in vivo. SCCVII cells $\left(5 \times 10^{5}\right)$ were inoculated subcutaneously into the right flank of $\mathrm{C} 3 \mathrm{H} / \mathrm{HeJ}$ mice, and 5 days later they were also inoculated into the left flank as metastasis models. Only the right palpable tumors, $6 \mathrm{~mm}$ in diameter, 6 days after inoculation into the right flank, were used for treatment. Bilateral tumor size was measured by vernier caliper for 21 days after treatment, and the tumor size was determined by $0.5 \mathrm{x}(\mathrm{W}+\mathrm{w})$, where $\mathrm{W}$ and $\mathrm{w}$ indicated longer and shorter width $(\mathrm{mm})$, respectively.

Treatment methods and groups in vivo. MCLs were injected longitudinally into each right cancer nodule of group II-IV mice. The mice were then classified into 4 groups, including group I (non-treated as a control), group II $\left(43^{\circ} \mathrm{C} \mathrm{HT}+\mathrm{iDC}\right)$, group III $\left(43^{\circ} \mathrm{C} \mathrm{HT}+41^{\circ} \mathrm{C} \mathrm{mHT}\right)$ and group IV $\left(43^{\circ} \mathrm{C} \mathrm{HT}+\right.$ $\left.\mathrm{iDC}+41^{\circ} \mathrm{C} \mathrm{mHT}\right)\left(\mathrm{n}=8\right.$ for each group). First, $43^{\circ} \mathrm{C} \mathrm{HT}$ was carried out for $30 \mathrm{~min}$ in all but group I. Twenty-four hours after first HT, $2 \times 10^{6}$ iDC were injected into the tumors of group II and group IV mice, while group I and group III tumors were injected with PBS. Immediately thereafter, groups III and IV were given additional $\mathrm{mHT}$ at $41^{\circ} \mathrm{C}$ for $30 \mathrm{~min}$. The protocol is shown in Fig. 2.

HT was performed by exposure to an alternating magnetic field (AMF) using a vertical coil with a transistor inverter (LTG-100-05, Dai-Ichi High Frequency, Tokyo, Japan). Tumor temperature was measured by optical fiber probe (FX-9020; Anritsu Meter). Magnetic field intensity was adjusted to maintain the temperature of the overlaying skin at approximately $43^{\circ} \mathrm{C}$ at first $\mathrm{HT}$ and $41^{\circ} \mathrm{C}$ at additional mHT.

Immunofluorescent staining of CD8-positive cells in tumor. To investigate the infiltration of CD8-positive cells for tumor suppression, another in vivo assay was performed $(\mathrm{n}=3$ for each group). Seven days after treatment, bilateral tumor tissues in each group were resected and fixed with formaldehyde, embedded with OCT compound and then sliced into sections. Those sections were stained with hematoxylin-eosin (HE), and CD8-positive T cells infiltrating tumor tissues were detected by immunofluorescent staining. The primary antibodies used 
SCCVII cells injection into right flank

$$
\sqrt{5} \text { days }
$$

SCCVII cells injection into left flank

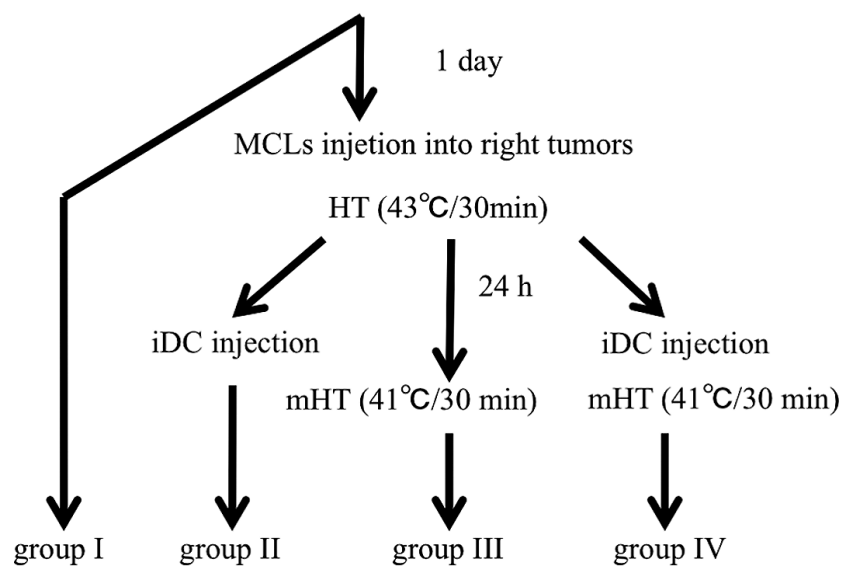

Figure 2. In vivo treatment methods and groups. The mice were classified into 4 groups, including group I (non-treated as a control), group II (HT $+\mathrm{iDC})$, group III $(\mathrm{HT}+\mathrm{mHT})$ and group IV $(\mathrm{HT}+\mathrm{iDC}+\mathrm{mHT})(\mathrm{n}=8$ for each group). First, HT was carried out for $30 \mathrm{~min}$ in all but group I. Twenty-four hours after first HT, $2 \times 10^{6}$ iDC were injected into the tumors of groups II and IV mice, while groups I and III tumors were injected with PBS. Immediately thereafter, groups III and IV were given additional mHT for $30 \mathrm{~min}$.

in this study were anti-mouse CD8a (eBioscience; 1:200). Binding of primary antibodies to these cells was detected using Alexa Fluor 488-conjugated anti-mouse IgG (Molecular Probes, Inc., Eugene, OR, USA). Cell nuclei were stained with DAPI (Vectashield ${ }^{\circledR}$; Vector Laboratories, Inc., Burlingame, CA, USA).

Statistical analysis. Levels of statistical significance in the tumor-growth and cell density experiments were evaluated using one-way ANOVA test. $\mathrm{P}<0.05$ was considered significant. For survival analysis, the differences in survival rates were analyzed by log-rank test.

\section{Results}

Alteration of HSP70 expression in SCCVII cells. Inducible HSP70 expression was examined using heat-shocked SCCVII cells. Fig. 3A shows the results of Western blotting under different temperatures and incubation periods after heating. SCCVII cells expressed the largest amount of HSP70 after heating at $43^{\circ} \mathrm{C}$ for $30 \mathrm{~min}$ with a $24-\mathrm{h}$ incubation period. Conversely, inducible HSP70 expression in non-heated cells was not detected by Western blot analysis (data not shown).

iDC maturation in vitro (expression of $C D 80$ and $M H C$ class II). As shown in Fig. 3B and C, molecules of CD80 and $\mathrm{MHC}$ class II expression were upregulated in groups $\mathrm{C}$ and $\mathrm{D}$ (positive control). Interestingly, the DC did not mature with single conventional HT (group B) like the non-treated group (group A), as previously reported of other cancer. In addition, there was no upregulation of these molecules under $41^{\circ} \mathrm{C}$ heating after coculture with non-heated or $41^{\circ} \mathrm{C}$-heated
A
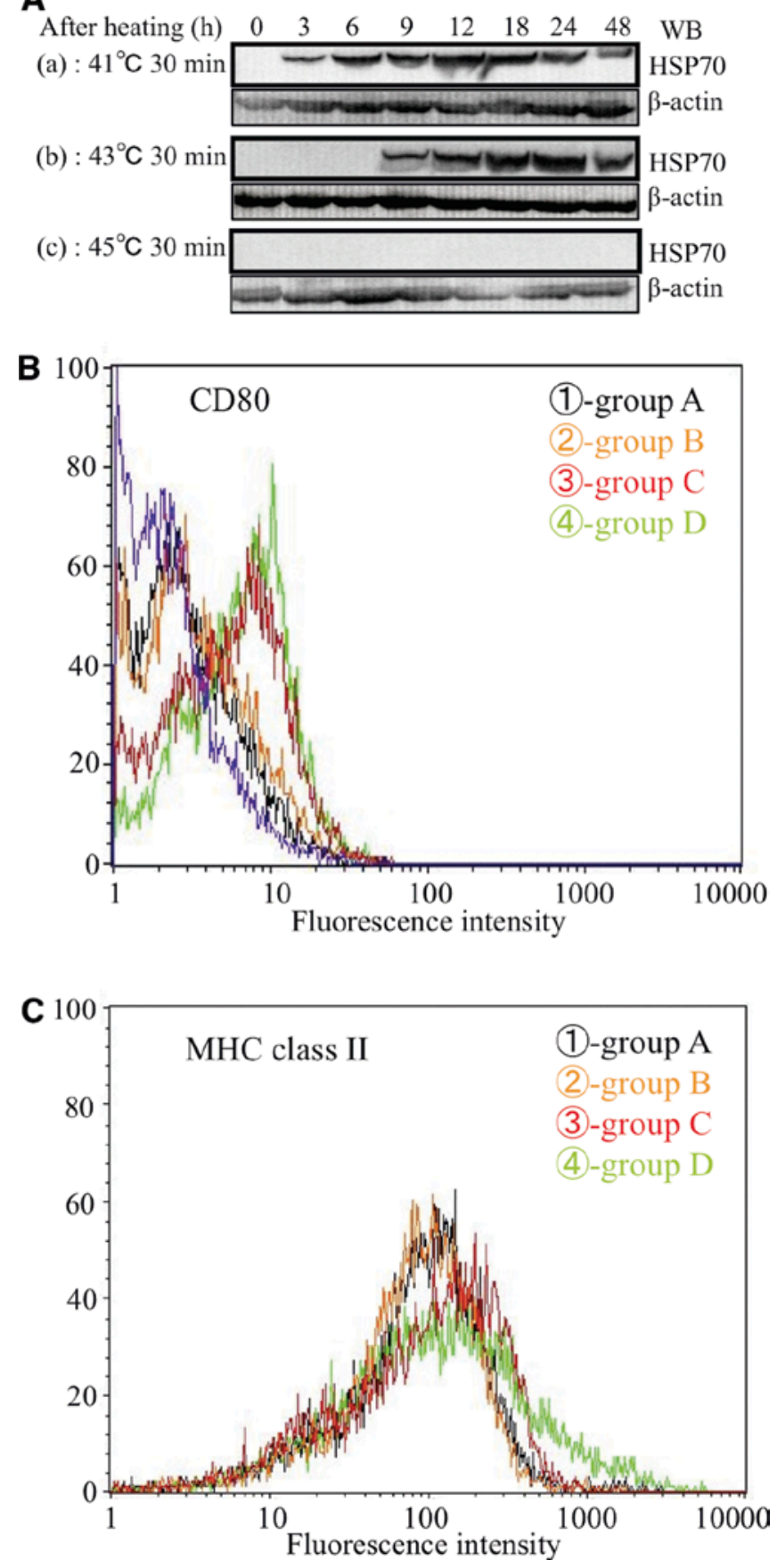

Figure 3. (A) HSP70 expression in heated SCCVII cells. Time course of HSP70 expression after (a) $41^{\circ} \mathrm{C} / 30 \mathrm{~min}$ (b) $43^{\circ} \mathrm{C} / 30 \mathrm{~min}$, and (c) $45^{\circ} \mathrm{C} / 30 \mathrm{~min}$ heating. SCCVII cells expressed the largest amount of HSP70 after heating at $43^{\circ} \mathrm{C}$ for $30 \mathrm{~min}$ with a $24-\mathrm{h}$ incubation period. (B) The expression of DC costimulating factor CD80 and (C) MHC class II after coculture. Cell surface phenotypes of DCs which were pulsed with non-heated SCCVII cells (group A), heated SCCVII cells (group B), given mHT under coculture (group C), or LPS (group D; positive control) were then investigated. Both $\mathrm{CD} 80$ and $\mathrm{MHC}$ class II expression were upregulated in group $\mathrm{C}$ as same level of positive control compared with groups A and B. No significant differences in the expression were found between groups A and B.

SCCVII, and heating DC alone (data not shown). These results indicate that not only heating SCCVII cells alone, but also mild heating of DC itself is more important to induce its maturation in vitro. 

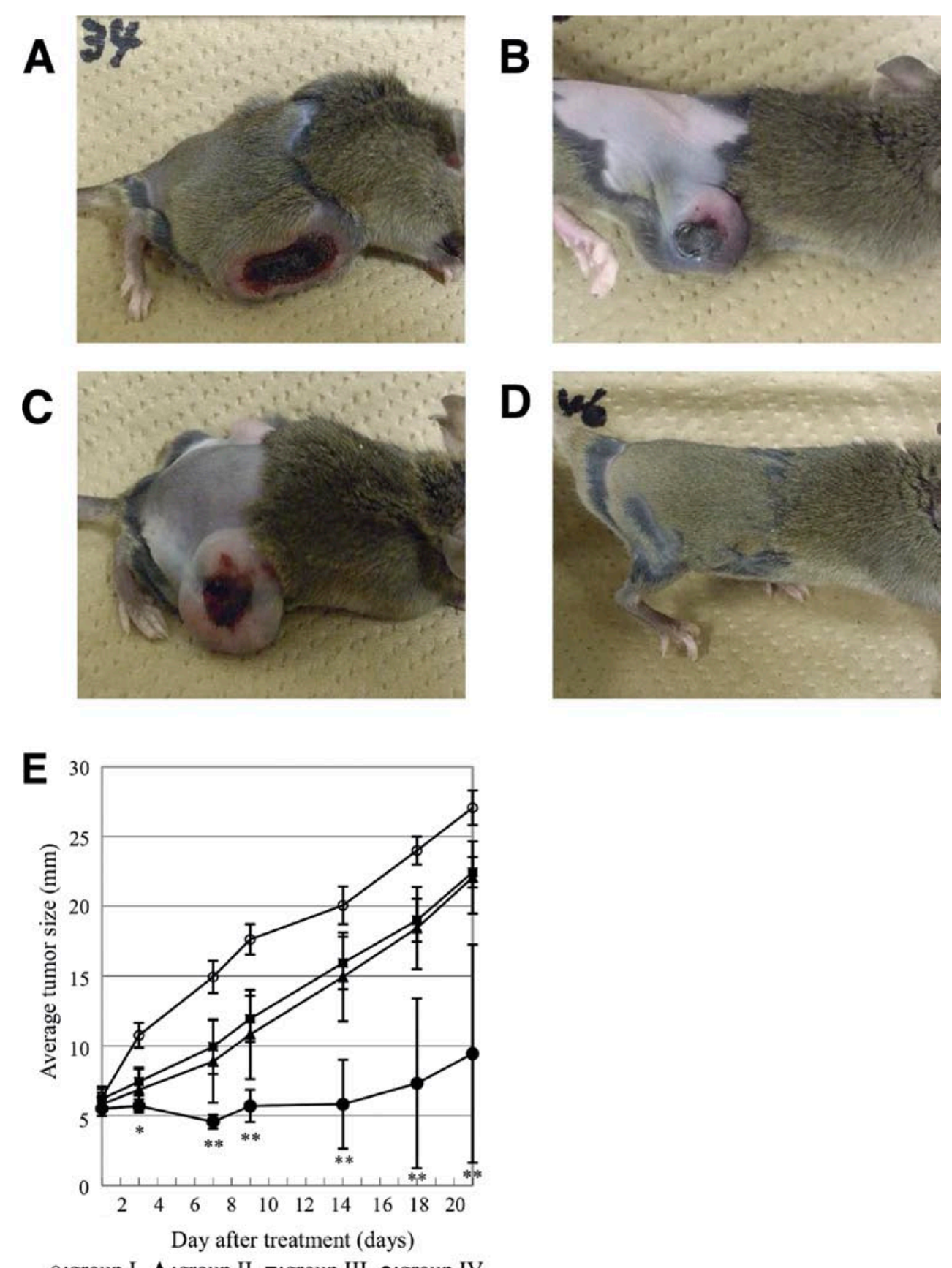

○:group I $\boldsymbol{\Lambda}$ :group II $\boldsymbol{m}$ :group III •:group IV

Figure 4. A case of in vivo-treated mice and average growth curve of treated right tumors in each group. Photographs which indicate (A) group I, (B) group II, (C) group III, (D) group IV were taken 14 days after initiation of treatment. (E) Average growth curve of treated right tumors $(\mathrm{n}=8)$. Tumor growth was suppressed in groups II and III in comparison with the control group. In group IV, tumor growth was obviously suppressed compared with the other groups. "P $<0.05,{ }^{* *} \mathrm{P}<0.01$.

Therapeutic effect of hyperthermia plus DC in vivo. The therapeutic effects of combined therapy of MCL-induced HT and iDC therapy were assessed in vivo. Fig. 4A-D and Fig. 5A-D show representative treated right tumors and nont-reated left metastatic tumors of each group 14 days after treatment, respectively. Figs. 4E and 5E show the right average tumor size and the left one after treatment. In group I, bilateral tumors grew progressively. In the case of right tumors, which were on the primary treatment side, tumor growth was suppressed in groups II and III in comparison with the control group $(\mathrm{P}<0.05)$. Interestingly, tumor growth was obviously suppressed in group IV compared with the other groups $(\mathrm{P}<0.01)$. Complete tumor regression was observed in 3 of 8 mice in group IV. In the case of left tumors, which was the non-treatment side, no tumor suppression was observed in groups II and III. On the other hand, tumor growth was more suppressed only in group IV compared with the other groups $(\mathrm{P}<0.05)$.

Immunohistochemistry of tumor tissue. HE stainings of non-treated and $43^{\circ} \mathrm{C}$-heated tumor tissue are shown in Fig. 6 . Viable and proliferative tumor cells could be observed in 

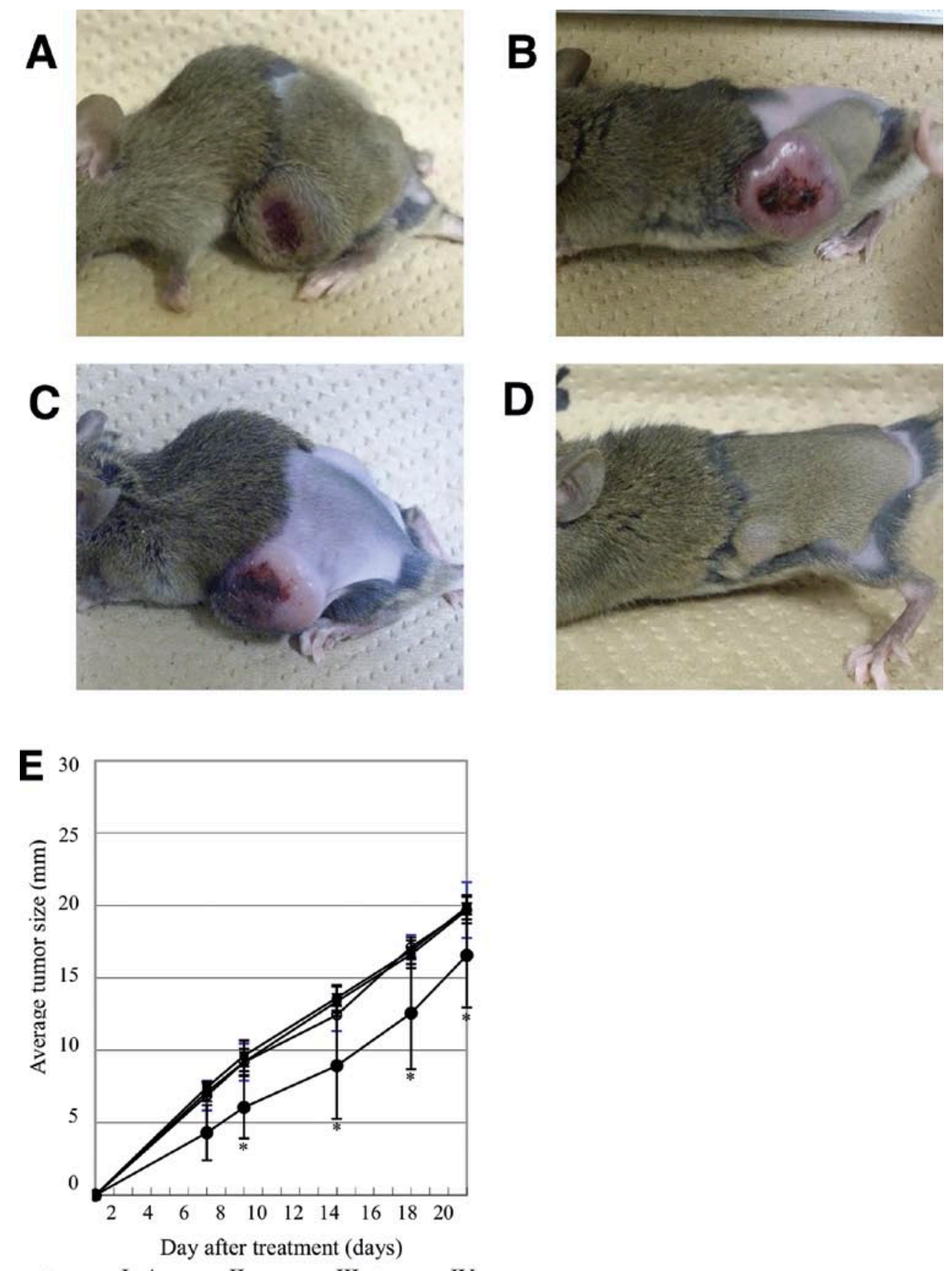

Figure 5. A case of in vivo-treated mice and average growth curve of non-treated left tumors in each group. Photographs which indicate (A) group I, (B) group II, (C) group III, (D) group IV were taken 14 days after initiation of treatment. (E) Average growth curve of non-treated left tumors (n=8). No tumor suppression was observed in groups II and III. On the other hand, tumor growth was more suppressed only in group IV compared with the other groups. ${ }^{*} \mathrm{P}<0.05$.
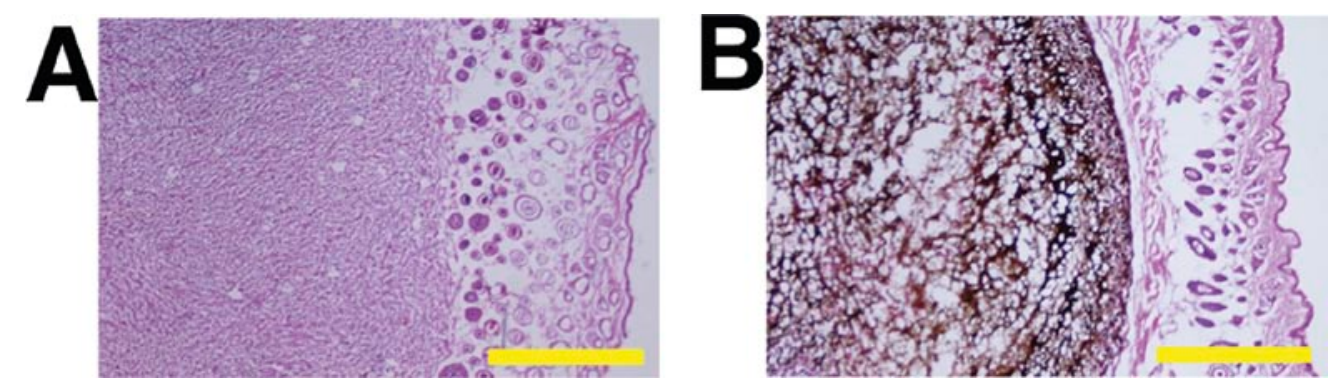

Figure 6. HE staining of non-treated (A) and $43^{\circ} \mathrm{C}$-heated (B) tumor tissues. Viable and proliferative tumor cells could be observed in non-treated tumors (A). On the other hand, in $43^{\circ} \mathrm{C}$-heated tumors, MCLs were spread and necrotic tumor cell death was partially observed (B). Bars, $1 \mathrm{~mm}$. 

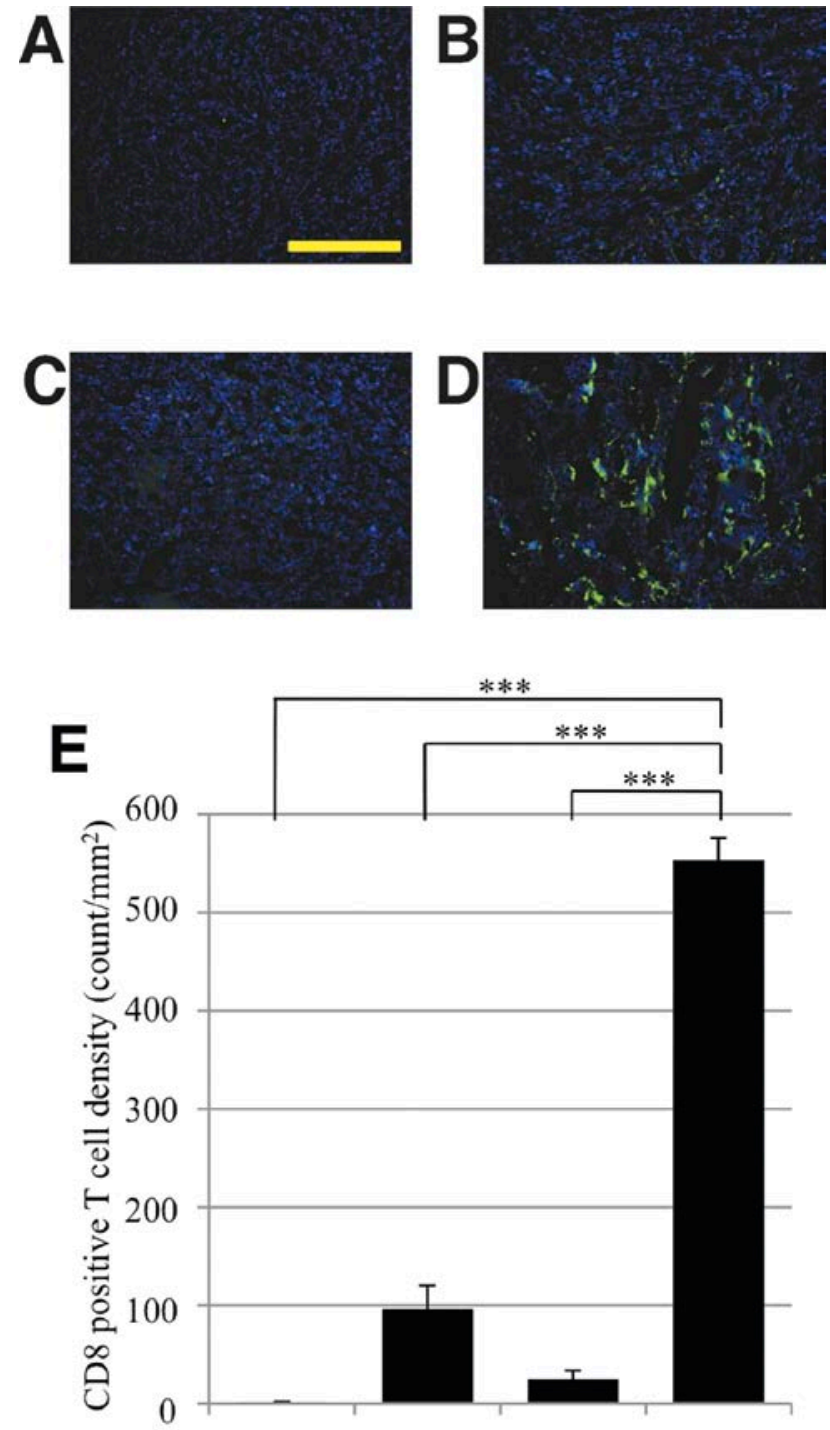

group I group II group III group IV

Figure 7. Immunofluorescent staining of CD8-positive cells infiltrating the treated right tumors in each group. Representative image of right tumors in group I (A), group II (B), group III (C) and group IV (D). CD8-positive T cells were frequently detected in mHT-added group IV. CD8-positive cell density was calculated in 10 random fields of three tumors in each group (E). The CD8 positive $\mathrm{T}$ cell density in group IV tumors was significantly higher compared with the other groups. ${ }^{* * *} \mathrm{P}<0.001$. Bar, $200 \mu \mathrm{m}$.

non-treated tumor. On the other hand, in $43^{\circ} \mathrm{C}$-heated tumor, MCLs were spread and necrotic tumor cell death was partially observed. Immunofluorescent stainings of CD8-positive cells infiltrating treated right tumors and non-treated left ones in each group are shown in Figs. 7A-D and 8A-D, respectively. CD8-positive cells can be assumed to be cytotoxic T cells. CD8-positive cell density was calculated in 10 random fields of tumors in each group by using Dynamic Cell Count (Keyence, Japan) (Figs. 7E and 8E). The CD8-positive $\mathrm{T}$ cell density in group IV tumors was significantly higher compared with the other groups in non-treated sides $(\mathrm{P}<0.01)$ as well as treated ones $(\mathrm{P}<0.001)$.

Lifetime is prolonged by additional mild hyperthermia. The survival rates of tumor-bearing mice over a period of 80 days after HT are shown in Fig. 9. All mice in group I died within
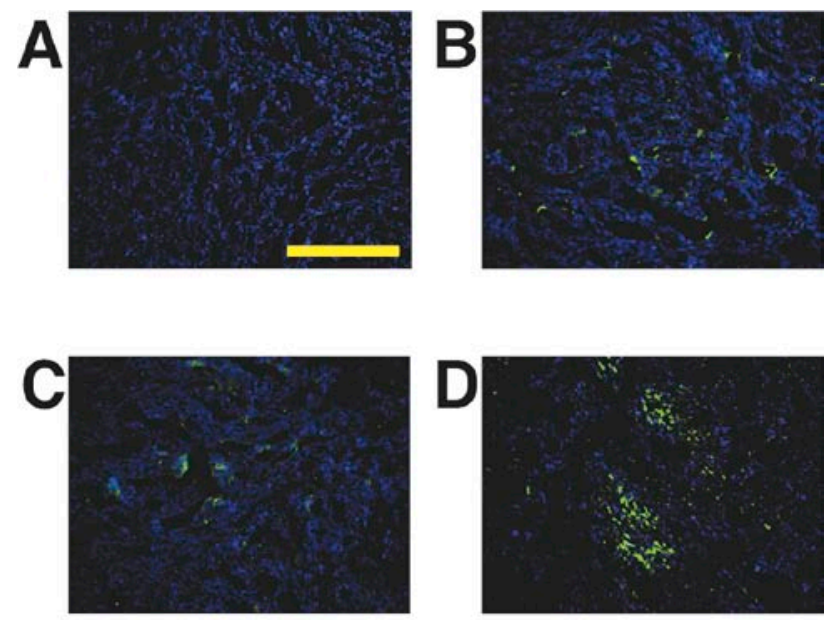

E

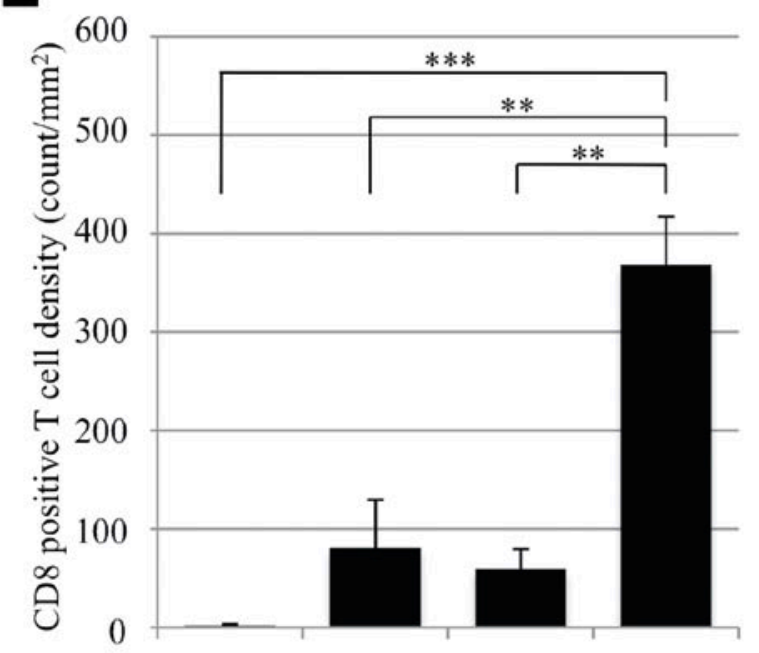

group I group II group III group IV

Figure 8. Immunofluorescent stainings of CD8-positive cells infiltrating non-treated left tumors in each group. Representative image of left tumors in group I (A), group II (B), group III (C) and group IV (D). CD8-positive cell density was calculated in 10 random fields of three tumors in each group (E). The CD8-positive $\mathrm{T}$ cell density in group IV tumors was significantly higher compared with the other groups as well as treated side. ${ }^{* *} \mathrm{P}<0.01,{ }^{* * *} \mathrm{P}<0.001$. Bar, $200 \mu \mathrm{m}$.

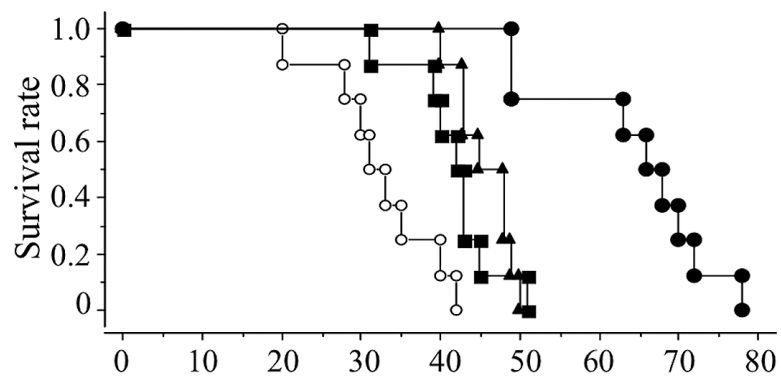

Day after the treatment (days)

०:group I $\boldsymbol{\Delta}$ :group II $\mathbf{a}$ :group III •:group IV

Figure 9. Survival rates of mice in each group. All mice in group I died of enlarged tumors at the inoculated site within $\sim 40$ days. Survival was slightly prolonged in groups II and III. Further lifetime prolongation was observed in the mHT-added group IV compared with the other groups $(\mathrm{P}<0.05)$ 
42 days from the enlarged tumor at the inoculated site. Survival was significantly prolonged but differences in groups II and III were small compared with group I $(\mathrm{P}<0.05)$. There was no significant difference between groups II and III. Further lifetime prolongation was observed in group IV compared with groups II and III $(\mathrm{P}<0.01)$. Even if a right-sided tumor in a group IV mouse disappeared, the mouse eventually died of an untreated tumor on the left side which gradually enlarged. These results indicate that the survival of SCCVII-burdened mice was prolonged by mHT combined with HT and iDC injection.

\section{Discussion}

In this study, we demonstrated the efficacy of HT and DC for SCC in mice. This is the first report of effective combined treatment of HT and DC for SCC. However, this therapeutic strategy did not work by single treatment (only simple HT + DC), which has been reportedly effective for various other cancers.

The HSP70 vaccination effect for tumor treatment was reported to be directly dependent on the dose of HSP70 (13). Thus, we initially demonstrated the condition in which the dose of HSP70 expression in SCCVII cells could be maximum. Instead of the maximum condition of HSP70 expression, cocultured iDCs were hardly matured in this study. On the other hand, in a similar experiment using mouse B16 melanoma cells, apparent DC maturation was attained when iDCs were cocultured with heated tumor cells (6). The reason for these disappointing results is speculated to be that SCCVII cells are poorly immunogenic cell strains (14). For such poorly immunogenic cancers, we considered that not only tumor lethal temperature heating but also other treatment modalities are required.

Recently, mHT has been found to enhance the primed DC ability to initiate and regulate immune responses. In this study, we investigated the feasibility of a new therapeutic modality for additional $\mathrm{mHT}$ in murine SCC. As shown in in vitro FACS analysis on CD80 and MHC class II expression of DC, DC hardly matured during 72-h coculture with SCCVII cells which were preheated only at $43^{\circ} \mathrm{C} / 30 \mathrm{~min}$ for $24 \mathrm{~h}$. In contrast, when DCs were co-cultured with preheated SCCVII cells for $24 \mathrm{~h}$ and additional mHT was given, a high level of DC maturation was induced. Several different thermally sensitive aspects of DC have been identified beginning with antigen uptake and including T-cell stimulation and cytokine production (8). Physiological increases in temperature might thus be used as an exogenous danger signal to help mature DCs achieve a state in which they activate antigen-specific $\mathrm{T}$ cells, instead of deleting these cells and reinforcing peripheral tolerance as immature DCs are presently thought to do $(15,16)$. This highlights the potential use of elevated temperature to help overcome immune tolerance to tumors. Indeed, the studies outlined here support various clinical uses of HT as part of an immunotherapeutic strategy in cancer treatment. Based on these studies, there are several thermally sensitive points that could be approached sequentially or through systemic treatments. Since DCs are known to play a role in the initiation of the immune response and later at the effector stage in a tumor, applying hyperthermic treatment at both of these time-points may be advantageous. No existing data indicate which protocol would be better (8).

In our study, with bilateral tumor-bearing mice, additional mHT was more effective for not only treated but also nontreated tumors. We speculated as to the mechanisms of these phenomena. Local HT first upregulated the generation of HSP70 in SCCVII cells. iDC injection into the heated tumor $24 \mathrm{~h}$ after local HT made iDC induce tumor-specific antigen uptake and presentation more possible. mHT just after iDC injection would enhance the DC function, such as antigen uptake and presentation, migration to lymph nodes, maturation, cytokine release and T-cell stimulation. In this study, especially the function of antigen uptake would thereby be enhanced substantially and lead to consequent maturation.

The immunohistochemical study showed that the level of CD8-positive $\mathrm{T}$ cell infiltration of the tumor in $\mathrm{mHT}$ added group was significantly higher even in non-treated sides than that in the other treated groups. Our data indicate that vaccine effect with stimulated DCs by HT and $\mathrm{mHT}$ are profound and suppress the tumor growth. Furthermore, lifetime was also prolonged by additional $\mathrm{mHT}$. These results would indicate that the above-mentioned 3-step process $(\mathrm{HT}, \mathrm{iDC}+\mathrm{mHT})$ is fundamental to activate DC and assure consequent maturation and tumor-specific T-cell activation. In contrast, various cytokine supplement therapies have been reported to be more efficient when combined with hyperthermia or DC therapies (17). Indeed, cytokine therapies have several serious immunological side-effects, and it would be difficult to perform these therapies in clinical application or by limiting the clinical doses; this would mean sufficient effects could not be obtained. However, HT, especially mHT, has virtually no adverse consequences, and the frequency of therapy is not limited. Furthermore, the more frequent heating is performed, the more curative effect could be obtained by activating the immune system. mHT has been revealed to activate not only DCs but also other immune cells $(18,19)$.

In MCL-mediated hyperthermia, once MCLs are injected into the tumor, it is possible to heat the tumor several times by exposure to AMF (20). Injected MCLs gradually diffuse into the surrounding tissue, so another important advantage is the safety of this MCL-mediated modality. MCLs are comprised of cationic lipid and magnetite, and each component has already been introduced into clinical use. Thus, even in the repeated injection of MCL, there is virtually no possibility of iron deposition in vital organs nor is there any effect on survival in the animal model. The safety of MCLs has been established.

Based on these results, the above-mentioned 3-step process could be one of the novel protocols which can upregulate a tumor-specific immune system with little risk of adverse sideeffects. In future work, the involvement of anti-tumor immunity should be further investigated. Consequently, presently incurable recurrent cancers and metastasis will be suppressed, and the survival rate will also be improved by the application of this combined therapy.

\section{Acknowledgements}

The authors wish to thank A. Ogata for technical assistance. 


\section{References}

1. Menoret A and Chandawarkar R: Heat-shock protein-based anticancer immunotherapy: an idea whose time has come. Semin Oncol 25: 654-660, 1998.

2. Nakajima M, Kuwano H, Miyazaki T, Masuda N and Kato $\mathrm{H}$ : Significant correlation between expression of heat shock proteins 27,70 and lymphocyte infiltration in esophageal squamous cell carcinoma. Cancer Lett 178: 99-106, 2002.

3. Basu S, Binder RJ, Ramalingam T and Srivastava PK: CD91 is a common receptor for heat shock proteins gp96, hsp90, hsp70, and calreticulin. Immunity 14: 303-313, 2001.

4. Melcher A, Todryk S, Hardwick N, Ford M, Jacobson M and Vile RG: Tumor immunogenicity is determined by the mechanism of cell death via induction of heat shock protein expression. Nat Med 4: 581-587, 1998.

5. Theriault JR, Mambula SS, Sawamura T, Stevenson MA and Calderwood SK: Extracellular HSP70 binding to surface receptors present on antigen presenting cells and endothelial/epithelial cells. FEBS Lett 579: 1951-1960, 2005.

6. Tanaka K, Ito A, Kobayashi T, et al: Intratumoral injection of immature dendritic cells enhances antitumor effect of hyperthermia using magnetic nanoparticles. Int J Cancer 116: 624-633, 2005.

7. Tanaka K, Ito A, Kobayashi T, et al: Heat immunotherapy using magnetic nanoparticles and dendritic cells for T-lymphoma. J Biosci Bioeng 100: 112-115, 2005.

8. Ostberg JR and Repasky EA: Emerging evidence indicates that physiologically relevant thermal stress regulates dendritic cell function. Cancer Immunol Immunother 55: 292-298, 2006.

9. Suzuki S, Narita Y, Yamawaki A, et al: Effects of extracellular matrix on differentiation of human bone marrow-derived mesenchymal stem cells into smooth muscle cell lineage: utility for cardiovascular tissue engineering. Cells Tissues Organs 191: 269-280, 2010.
10. Calderwood SK, Theriault JR and Gong J: How is the immune response affected by hyperthermia and heat shock proteins? Int J Hyperthermia 21: 713-716, 2005.

11. Inaba $\mathrm{K}$, Inaba M, Romani $\mathrm{N}$, et al: Generation of large numbers of dendritic cells from mouse bone marrow cultures supplemented with granulocyte/macrophage colony-stimulating factor. J Exp Med 176: 1693-1702, 1992.

12. Shinkai M, Yanase M, Honda H, Wakabayashi T, Yoshida J and Kobayashi T: Intracellular hyperthermia for cancer using magnetite cationic liposome: in vitro study. Jpn J Cancer Res 87: 1179-1183, 1996.

13. Udono $\mathrm{H}$ and Srivastava PK: Comparison of tumor-specific immunogenicities of stress-induced protein gp96, hsp90, and hsp70. J Immunol 152: 5398-5403, 1994.

14. Khurana D, Martin EA, Kasperbauer JL, et al: Characterization of a spontaneously arising murine squamous cell carcinoma (SCCVII) as a prerequisite for head and neck cancer immunotherapy. Head Neck 23: 899-906, 2001.

15. Reis e Sousa C: Activation of dendritic cells: translating innate into adaptive immunity. Curr Opin Immunol 16: 21-25, 2004

16. 't Hart BA and van Kooyk Y: Yin-Yang regulation of autoimmunity by DCs. Trends Immunol 25: 353-359, 2004.

17. Mukhopadhaya A, Mendecki J, Dong X, et al: Localized hyperthermia combined with intratumoral dendritic cells induces systemic antitumor immunity. Cancer Res 67: 7798-7806, 2007.

18. Hasday JD, Garrison A, Singh IS, et al: Febrile-range hyperthermia augments pulmonary neutrophil recruitment and amplifies pulmonary oxygen toxicity. Am J Pathol 162: 2005-2017, 2003.

19. Ellis GS, Carlson DE, Hester L, et al: G-CSF, but not corticosterone, mediates circulating neutrophilia induced by febrile-range hyperthermia. J Appl Physiol 98: 1799-1804, 2005.

20. Ito A, Shinkai M, Honda H, et al: Heat shock protein 70 expression induces antitumor immunity during intracellular hyperthermia using magnetite nanoparticles. Cancer Immunol Immunother 52: $80-88,2003$. 